\title{
VITAMIN C AND ANAEMIA
}

\author{
By SCOTT THOMSON, A. J. GLAZEBROOK AND W. G. MILLAR \\ WITH A DESCRIPTION OF A PHOTO-ELECTRIC COLORIMETER \\ By W. G. MILLAR
}

From the Departments of Bacteriology, Pathology and Clinical

Medicine, University of Edinburgh

(With Plates 1-3 and 4 Figures in the Text)

\section{INTRODUCTION}

IN an institution for adolescents the dietary contained only negligible amounts of vitamin $\mathrm{C}$. The boys were admitted from working class homes and had probably existed on less than the optimum amounts of vitamin $\mathrm{C}$ desired by the dieticians. Large amounts of ascorbic acid were required to produce tissue saturation of the boys and a number were given $50-200 \mathrm{mg}$. of ascorbic acid daily for over 2 months (Glazebrook \& Thomson, 1942). At the end of this period haemoglobin titrations were made in boys having ascorbic acid and in others.

Severe degrees of vitamin C deficiency resulting in clinical scurvy are frequently associated with an anaemia. This may be due to haemorrhage into the bone marrow and may occur only in the severer degrees of deficiency. The investigation was undertaken to determine whether or not mild degrees of vitamin C deficiency are associated with mild degrees of anaemia.

\section{Methods}

As the boys had no obvious anaemia, and only slight differences between the two groups could at the most be expected, an accurate method of measurement was sought.

A $1 \%$ solution of acid haematin was made by withdrawing $0.1 \mathrm{ml}$. of blood from a bold finger prick and adding to $9.9 \mathrm{ml} . \mathrm{N} / 10 \mathrm{HCl}$. Standardized pipettes were used.

The solution of acid haematin was estimated by means of a photo-electric colorimeter which had been standardized against Van Slyke estimations. The titrations were all made $4 \mathrm{hr}$. after the blood had been added to the acid.

It is admitted that a solution of acid haematin is not a true solution and always has a slight opacity. It was found, however, that 'solutions' gave the same reading even after keeping for a few days.

The average haemoglobin reading obtained in the control group of 133 boys on the institution diet was $89.5 \%$, and the average of 60 boys who had had 
large amounts of vitamin $\mathrm{C}$ for 2 months was $90.4 \%$. There was therefore no difference between the two groups.

When all the results of the two groups were considered together the following distribution of results was obtained:

$\begin{array}{lrrrrrrrrrrrrr}\text { Result (\%) } & 60 & 67 & 72 & 75 & 79 & 82 & 86 & 90 & 94 & 98 & 102 & 105 & 107 \\ \text { Frequency } & 1 & 0 & 3 & 5 & 15 & 17 & 26 & 35 & 39 & 34 & 17 & 3 & 1\end{array}$

These results are shown graphically in Text-fig. 1.

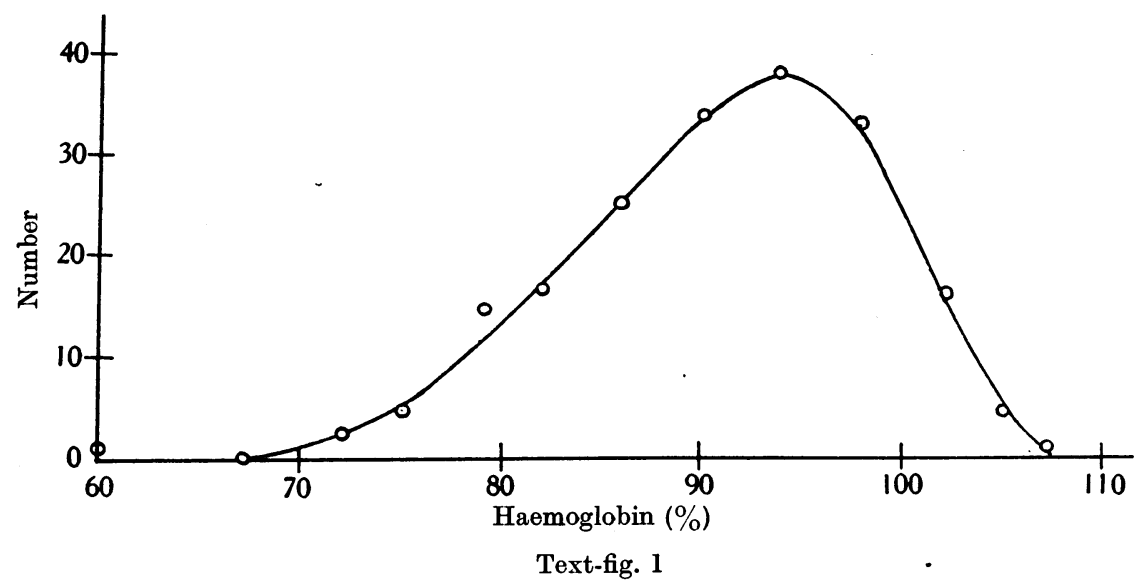

The curve was fairly smooth but somewhat skew. This would be expected, as the occurrence of slight degrees of anaemia is not balanced by slight degrees of polycythemia.

\section{Conclusion}

Mild degrees of vitamin $\mathrm{C}$ deficiency are probably not associated with mild degrees of anaemia.

The expenses of this work were met by grants from the Carnegie Universities' Fund and the Leverhulme Trust.

\section{REFERENCE}

Glazerrook, A. J. \& Thomson, S. (1942). J. Hyg., Camb., 42, 1-19.

\section{DESCRIPTION OF THE PHOTO-ELECTRIC COLORIMETER}

By W. G. MILLAR

"The apparatus described below and illustrated in Pls. 2 and 3 is designed to give objective readings in colorimetric work, using small quantities of material, namely, $2 \mathrm{ml}$. The principle involved is the use of a standard which is lighter in colour than the unknown and the subsequent diminution of the light passing through the 'standard' until the illumination is equal to that 
on the 'unknown' side (or the converse if the standard is denser than the unknown). The light control is by an arrangement of polarizing films, and equality of illumination is judged by means of a differential photo-electric cell and a suitable galvanometer. The instrument is a null-point one and continuous readings are therefore not obtainable. Direct reading with its attendant simplicity is not practicable unless the light source is run from a battery since the mains voltage has not the high standard of constancy required. The source of light used is a $100 \mathrm{~W}$. lamp of the ordinary mains projection type.

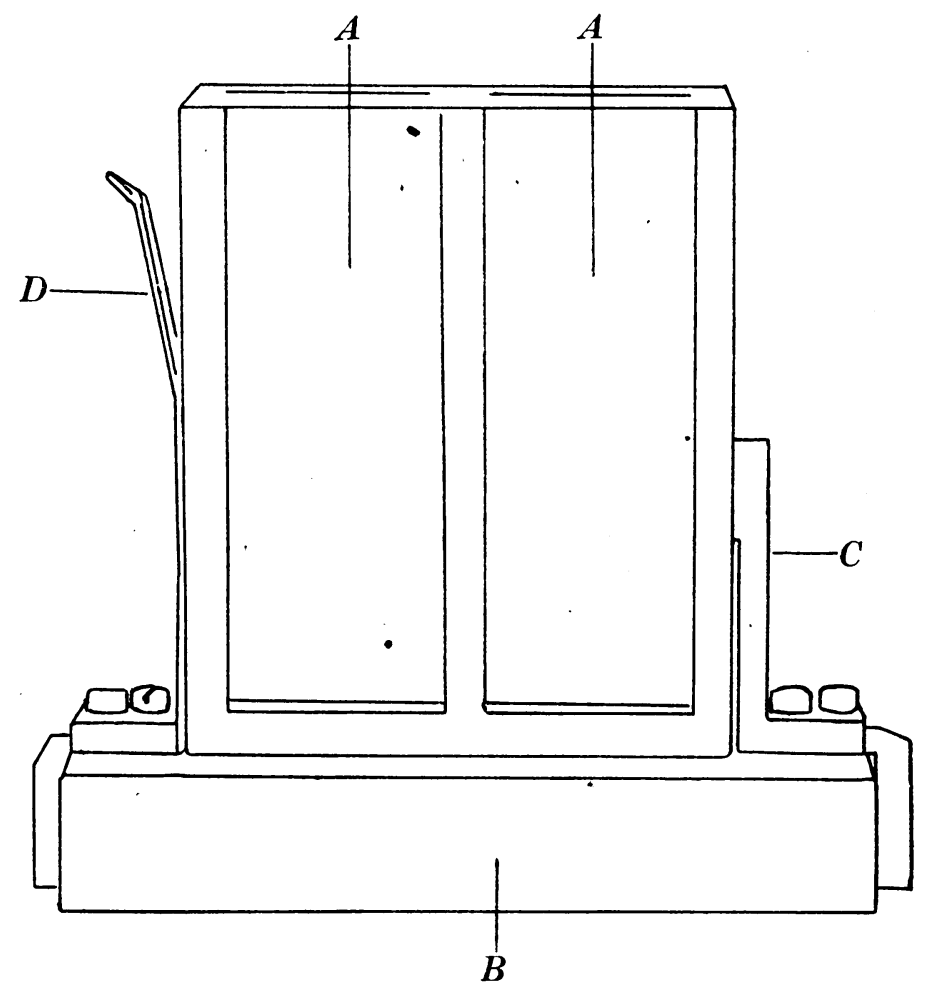

Text-fig. 2. Double glass cell $(A, A)$ containing solutions and holder $(B)$. $C$, stop. $D$, spring.

The 'unknown' and 'standard' solutions are contained in either compartment ( $A, A$, Text-fig. 2 ) of a small glass double cell. The central partition dividing the cell into the two compartments is only about $2 \mathrm{~mm}$. thick, and each compartment contains rather more than $2 \mathrm{ml}$. of fluid. Cells with a greater thickness of fluid can of course be used if required. The double cell is supported on a holder composed of a slab of brass ( $B$, Text-fig. $2,3 \times \frac{1}{2} \times \frac{3}{4}$ in.) on which it is held against a stop $(C)$ by a light spring $(D)$ (see also Pl. 1, fig. 1). The ends of the brass slab are provided with countersunk holes, in which work the points of two centring screws attached to the bracket to be mentioned later. By altering these screws the double cell.can be adjusted laterally. The 
double cell is united by vitreous cement and can therefore be cleaned in any of the ordinary solutions.

The photo-electric element is a differential green-sensitive cuprous oxide cell made by Westinghouse, although other types might be more suitable for certain colours. It is really two cells $(A, A$, Text-fig. 3$)$ side by side and separated by a hairline but forming one solid piece of material. Each half-cell measures $1 \times \frac{1}{2}$ in. of which about $\frac{3}{4} \times \frac{3}{8}$ in. is exposed to the'light. The remaining $\frac{1}{8}$ in. strip round the edges is occupied by the front electrical contact which is through the medium of $ᄃ$-shaped strips of a soft lead alloy. These strips intervene between the front surface of the light-sensitive cuprous oxide and two stout brass plates, $B B$, which form the front of the cell holder, the

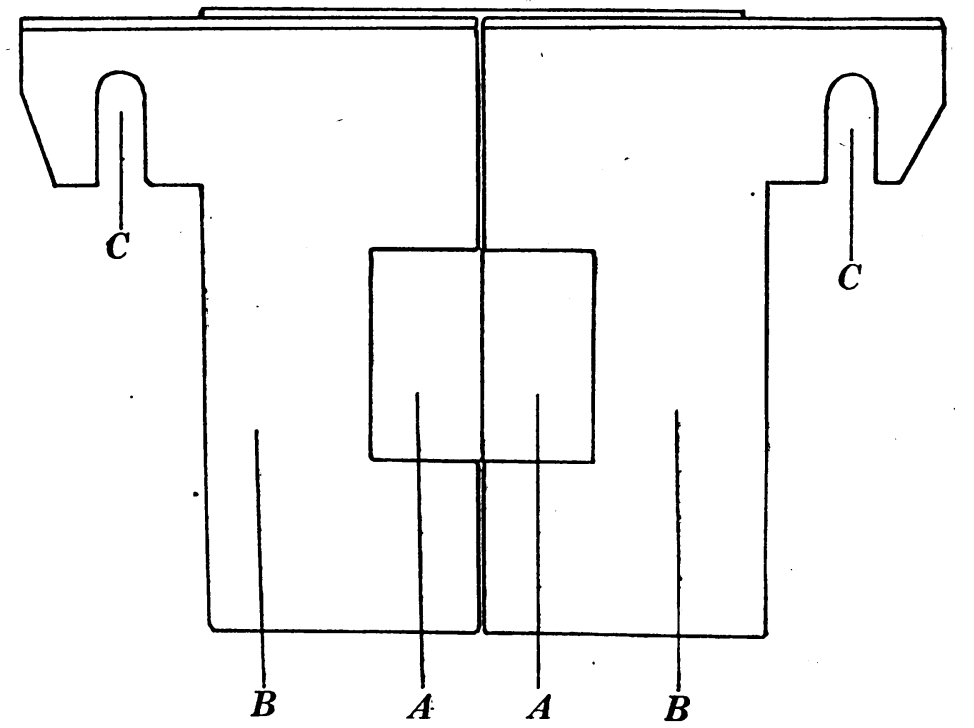

Text-fig. 3. Photo-electric element. $A, A$, cells. $B, B$, brass plate with slotted lugs $(C, C)$.

remainder of the casing being of ebonite. The two back surfaces of the cells are connected electrically by a stout brass plate, with intervening soft alloy, held firmly against the cuprous oxide by a spring bearing on the back of the ebonite casing. The plates are provided with projecting slotted lugs, $C C$, which fit over the terminals attached to two brass strips on the front panel of the instrument. Through these they are connected to the galvanometer. The front panel rises vertically from the base of the instrument. On the front it carries the light-equalizing device (Text-fig. 4) and the bracket holding the double glass cell. It is pierced with a $1 \times 1$ in. square aperture to admit light to the photo-electric cell, and the aperture is provided with a central vertical partition of thin black ebonite to minimize stray light.

Light falling on the front surfaces of the photo-electric element generates a small current in each half. Owing to the mode of connexion of the two 
halves the currents generated are in opposite senses, and if the light is of the same intensity on each half the resulting currents exactly neutralize and no current flows through the galvanometer. In practice the two half-cells are rarely of exactly the same sensitivity, and the more sensitive one may, if necessary, be shunted with a variable resistance of several thousand ohms by which it can be balanced.

The galvanometer used is a $140 \mathrm{ohm}$ (Type $4000 \mathrm{~A}$ ) by Tinsley and gives at $1 \mathrm{~m}$. scale distance, a deflexion of $560 \mathrm{~mm}$. per $\mu \mathrm{A}$. A scale is supported some 6 in. from the galvanometer mirror and is illuminated by a small spotlight operated from a bell transformer.

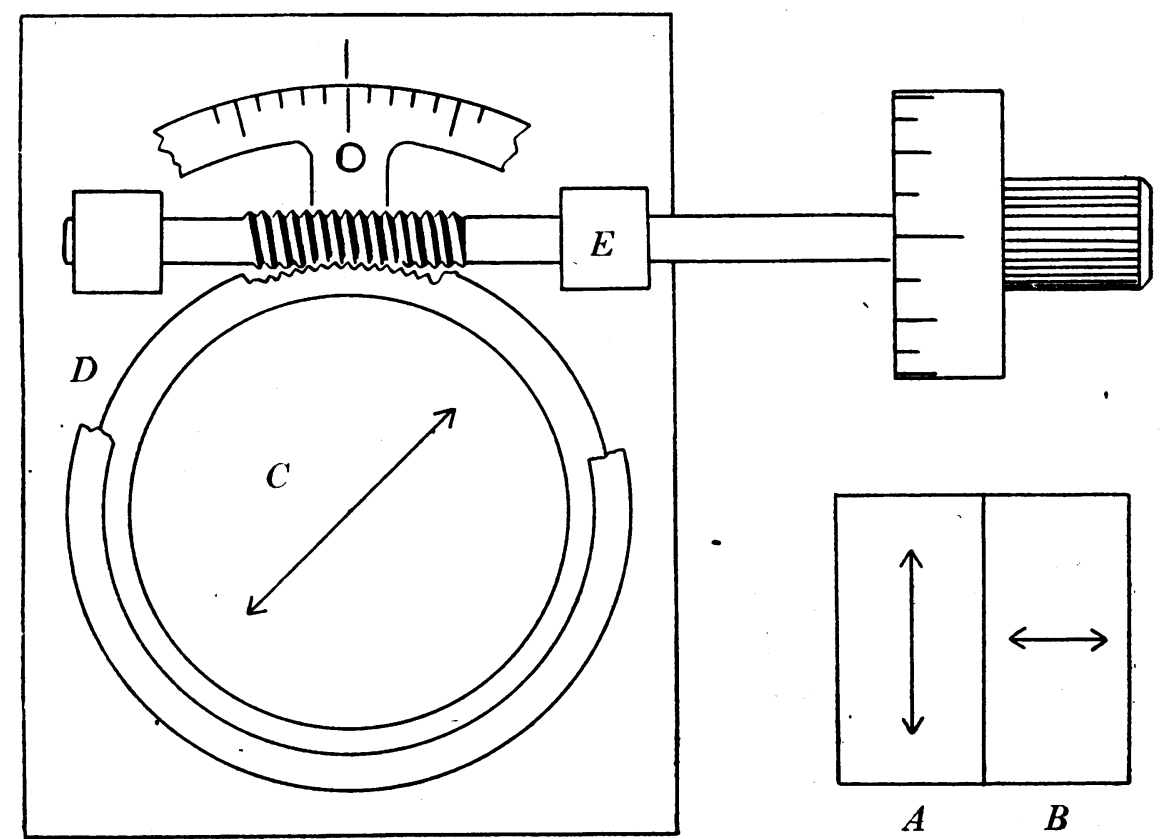

Text-fig. 4. Light-equalizing apparatus. $A, B$, two pieces of polaroid film composing half-shade. $C$, circular polaroid film. $D$, fitting of $C . E$, screw for rotating $D$.

The light-equalizing apparatus (Text-fig. 4) is in two parts. The first is a half-shade composed of two pieces of polaroid film, each $1 \times \frac{1}{2}$ in., in one of which, $A$, the polarizing axis is parallel to the long side, in the other, $B$, parallel to the short side. The two pieces are mounted in xylol balsam between two squares of glass so that two long sides are in apposition without appreciable overlap, and held in.the aperture in the ebonite front panel immediately in front of the photo-electric element, so that the dividing line of the halfshade is exactly in front of and parallel to the dividing line between the two halves of the photo-electric cell. The second part of the device is a circular polaroid film, $C, 1 \frac{1}{2}$ in. in diameter, contained in a brass fitting, $D$, by which it is held in front of the half-shade and in which it can be rotated by means 
of the tangent screw, $E$, provided with a graduated head. Means are also provided for reading whole rotations of the tangent screw. When the polarizing plane of the film $C$ is at $45^{\circ}$ to the mutually perpendicular planes of the half-shade the light transmission of the combination is the same for each half, but any alteration of this angle increases the transmission in one half-field and decreases it in the other. A general view of the instrument is shown in Pls. 2 and 3.

The method of using the instrument is as follows. The rotating polarizer is set at zero, i.e. the plane of polarization at $45^{\circ}$ to those of the half-shade. The light is switched on, and if there is any deflexion of the galvanometer this is reduced to zero by centring the lamp and if necessary by balancing the more sensitive cell by a high-resistance shunt. The empty and dry double cell is placed on its bracket and adjusted sideways until the reading is again zero. The unknown solution is put into one or other compartment of the double cell and an equal quantity of the standard (usually distilled water or other suitable 'blank' fluid) in the other. The galvanometer will now show a larger or smaller deflexion. This is reduced to zero by rotating the screw head, which by decreasing the light transmission on the side of the standard and increasing it on the side of the unknown restores the equality of light on the two halves of the photo-electric element. The reading of the scale now corresponds to the concentration of the unknown. Calibration curves are made in the usual way with serial dilutions of the required solutions.

Several precautions should be taken in using the apparatus. It is not advisable to leave the light running too long otherwise there may be slight heating of the solutions with the formation of air bells and consequent inaccuracy. Moreover, the photo-electric cell acts to some extent as a thermopile. It is essential, of course, always to use the same compartment of the double cell for the unknown as was used in calibration, since absolute accuracy in manufacture is not possible. Since the light is not collimated in any way, a certain amount is totally reflected from the surface of the fluids in the cells and may reach the photo-electric element. This reflexion will vary to some extent according to the amount of fluid in the cell and to the uniformity of the surface. Hence the same bulk of fluid should always be used, and any air bubbles cleared from the surface with a hot wire or similar means. The turning force on the galvanometer coil is proportional to the current and approximates to zero as the null point is approached. The instrument is thus rather sluggish in its response near the zero setting and takes a little time to assume its final position. It saves time and makes for precision if, instead of setting for absolute zero deflexion, a number of settings are made for small deflexions equidistant from zero on either side and an average taken. This, of course, is common practice in null-point methods. 
PLATE 1

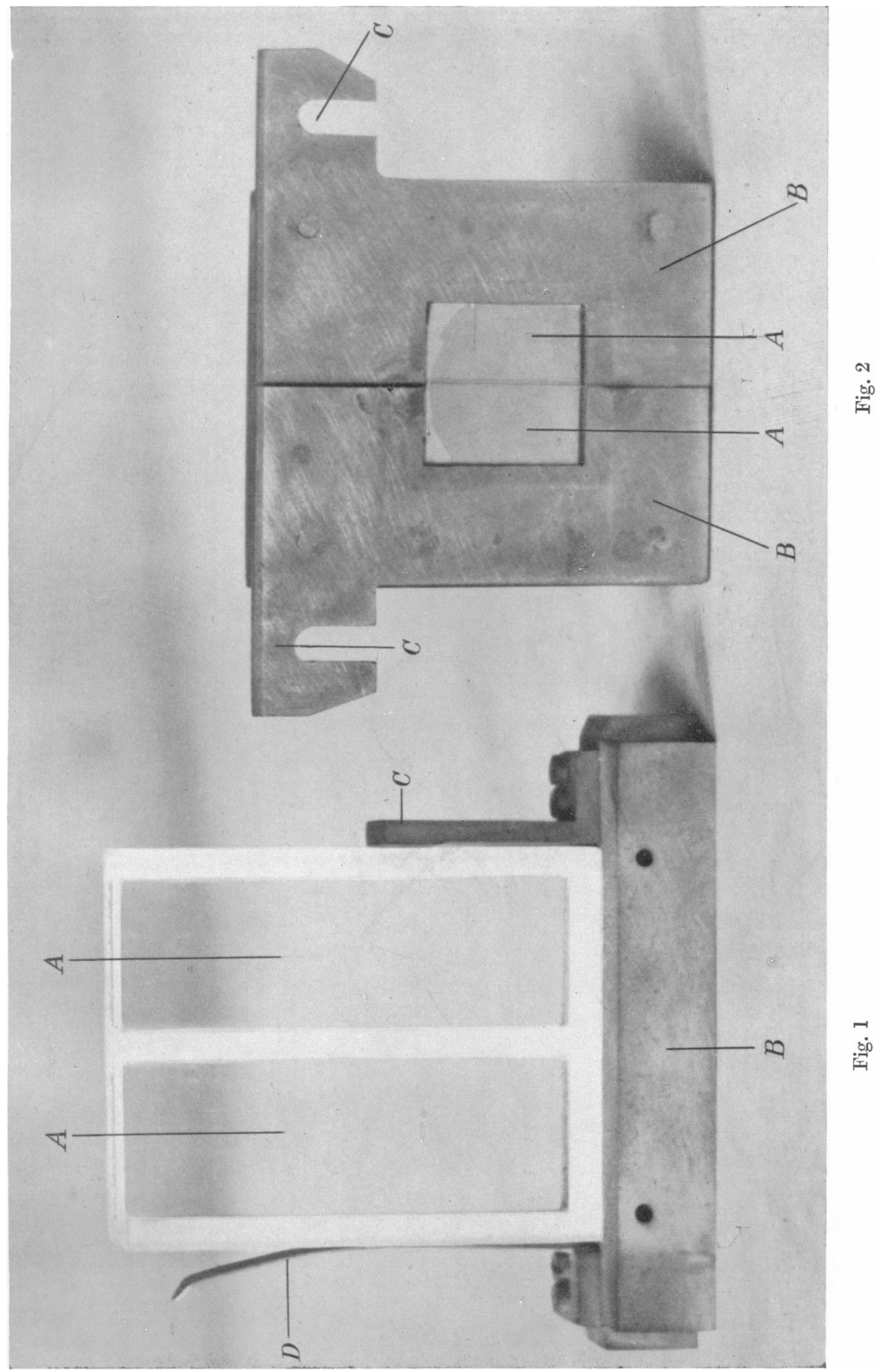




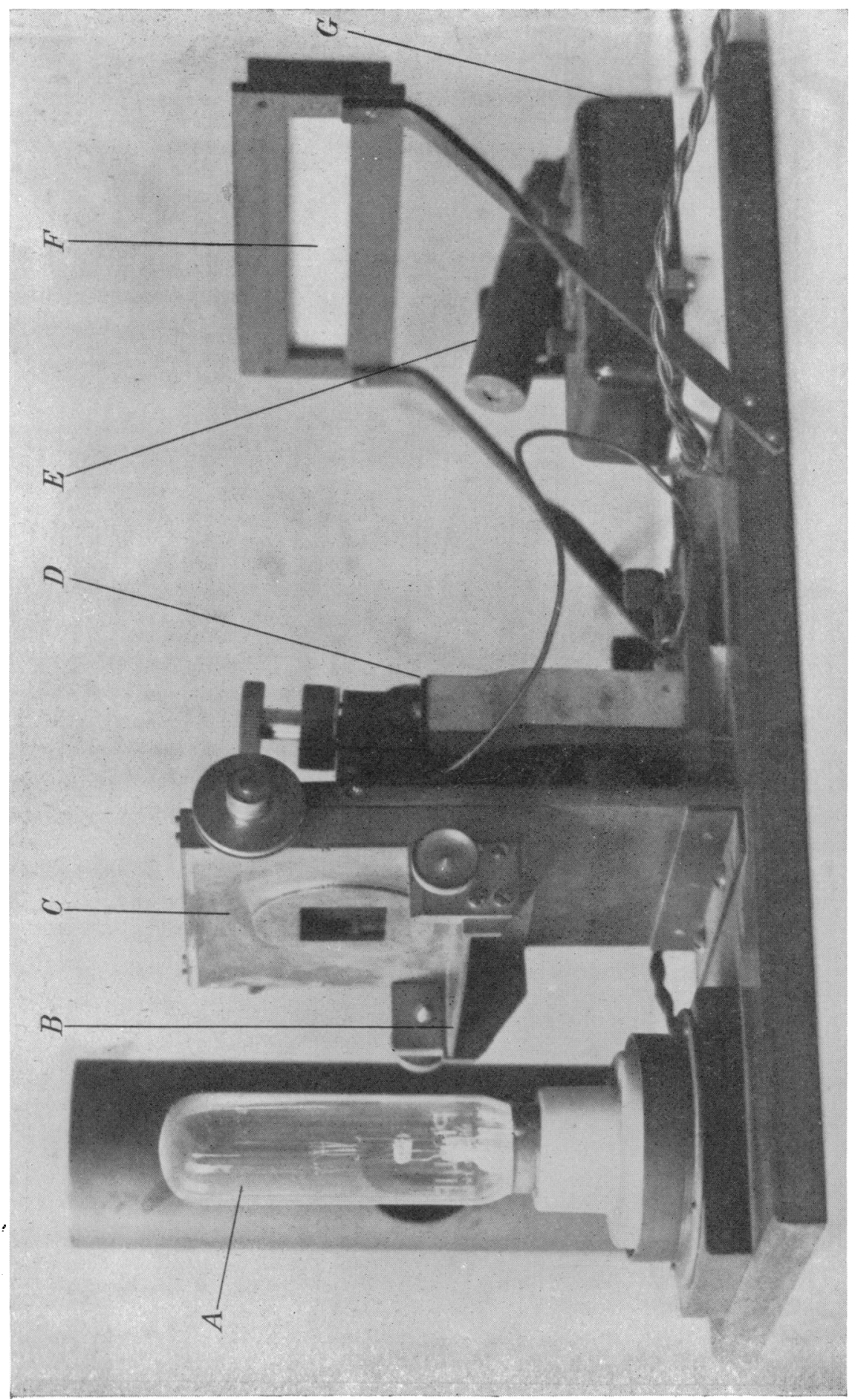




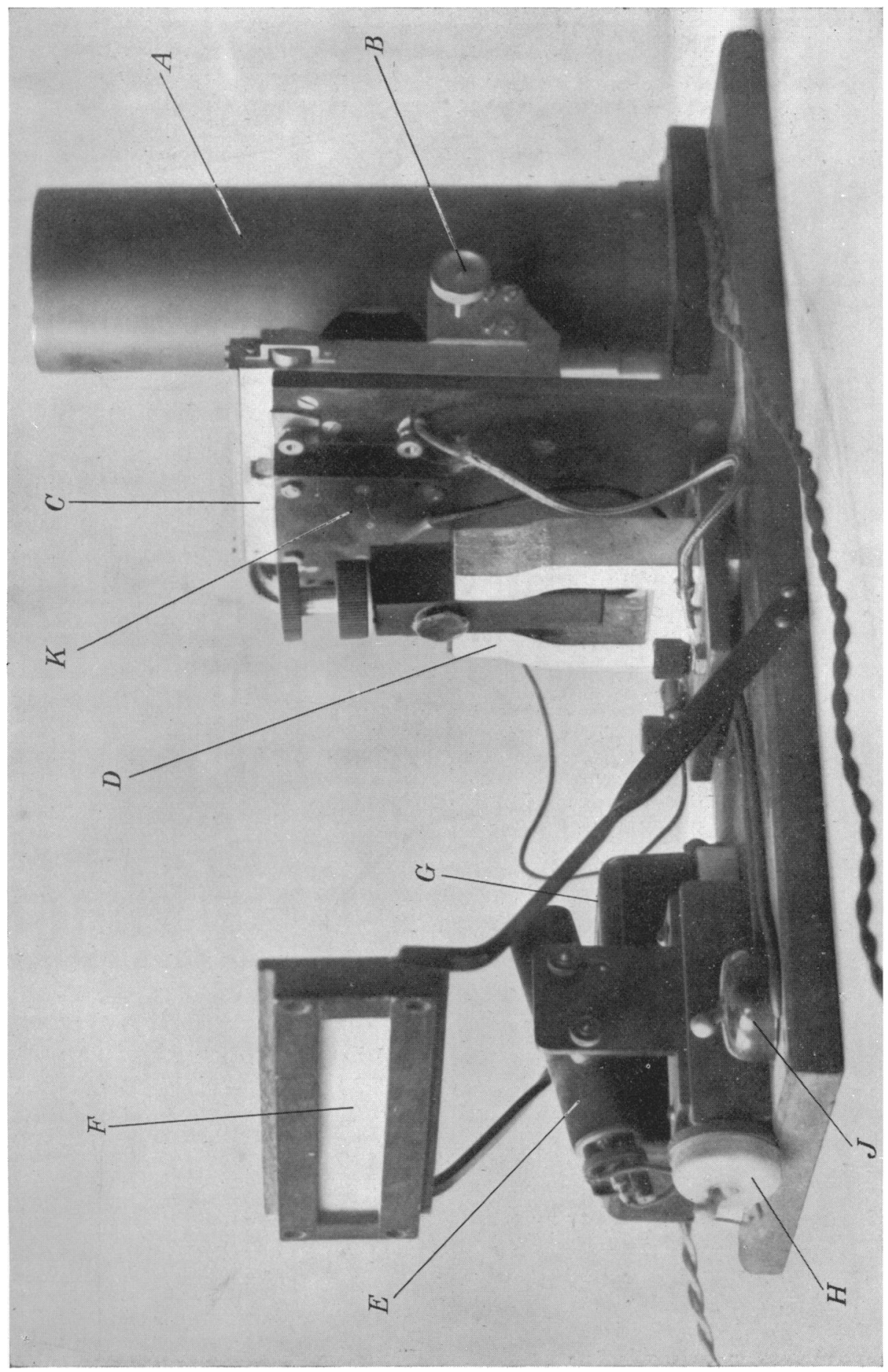




\section{SUMmary}

A new form of photo-electric photometer or colorimeter is described which permits of accurate and objective readings in a wide range of colorimetric work with small quantities of solutions. The instrument is of the null-point type and hence requires calibration to suit the particular estimation.

The writer is indebted to the Earl of Moray Fund of the University of Edinburgh for financial assistance towards the expenses of the earlier part of the work.

The original model was made by A. H. Baird of Edinburgh, the model described above by Wm. Watson and Sons, London, to whom, and to $\mathrm{Mr}$ W. E. Watson-Baker, I am indebted for suggestions on a number of points.

\section{EXPLANATION OF PLATES 1-3}

\section{PLATE 1 .}

Fig. 1. Double glass cell $(A, A)$ containing solutions and holder $(B)$. $C$, stop. $D$, spring.

Fig. 2. Photo-electric element. $A, A$, cells. $B, B$, brass plate with slotted lugs $(C, C)$.

PLATES 2 AND 3

General views of instrument

$A$, lamp and housing.

$F$, scale.

$B$, bracket to support double cell and

$G$, bell transformer for spot-light. holder.

$C$, light-equalizing apparatus.

$D$, galvanometer.

$\boldsymbol{E}$, spot-light for galvanometer.

$H$, on and off switch for spot-light.

$J$, short-circuiting switch to clamp galvanometer.

$K$, photo-electric cell.

(MS. received for publication 29. XII. 41.-Ed.) 